\title{
Snake Envenomation to the Face of a Child - Rare Case
}

Mustafa Șahan' ${ }^{1}$, Mehmet Duru', Koca Çalișkan', Ali Karakuș', Oğuzhan Özcan ${ }^{2}$,Ahmet Kahraman ${ }^{3}$, Güven Kuvandik ${ }^{1}$

${ }^{1}$ Department of Emergency Medicine, Faculty of Medicine, Mustafa Kemal University, Hatay, Turkey;

${ }^{2}$ Department of Biochemistry, Faculty of Medicine, Mustafa Kemal University, Hatay, Turkey;

${ }^{3}$ Department of Plastic and Reconstructive Surgery, Faculty of Medicine, Mustafa Kemal University, Hatay, Turkey

Received June 29, 2015; Accepted November 16, 2015.

Key words: Antivenom - Intubation - Pediatric case - Snakebite

Abstract: Snakebites are seen in summer season in the southern part of Turkey, including Hatay province. In average of 40 patients with snakebites are admitted to our hospital every year.Viper is the most common venomous snakes in our region. Their hemotoxins and necrotoxins lead to local or systemic tissue damage and is responsible for the mortality and morbidity. In this report, we described a rare pediatric case, a six-year-old boy having been bitten on the left side of his face when he was looking around from their home's balcony. The patient was orotracheally intubated and mechanically ventilated because of airway obstruction due to severe edema. 12 flacon of anti-snake venom, mannitol infusion, fresh frozen plasma, erythrocytes suspension and antibiotherapy were administered to the patient. Seven days after the admission, clinical and laboratory findings were improved and the patient was discharged in a good condition. Snakebites inflicted on face and neck areas may cause rapidly progressive edema in respiratory tract and lead to life-threatening conditions. Therefore early orotracheal intubation is very important to prevent mortality.

Mailing Address: Assoc. Prof. Ali Karakus, MD., Department of Emergency Medicine, Faculty of Medicine, Mustafa Kemal University, Hatay, Turkey; Mobile Phone: +90 50525404 33; Fax: +90 32624556 54; e-mail: drkarakus@yahoo.com 


\section{Introduction}

It is estimated that there are about 3,000 snake species in the World and fifteen percent of them have been reported to be venomous (Gold et al., 2002). In Turkey, only 16 of the 46 snake species are considered venomous (Baran, 2005). Approximately 40 snakebite cases are admitted to our hospital every year especially in summer seasons, when snakes and victims are more active. Crotalidae subfamily of the Viperidae family venom can be classified into five categories: hemotoxic, neurotoxic, necrotoxic, cardiotoxic and nephrotoxic. The most common venomous snake species, Vipera is present in the southern area of Turkey, including Hatay province (Baran, 2005). They both have hemotoxic and necrotoxic venoms. Snake venoms have various effects on the bitten site and on the whole body. It may presented with pain, edema, echymosis, lymphangitis, hemorrhagic bullae including puncture wounds at the bitten site, and life-threatening disorders such as renal failure, shock, bleeding and coagulation disorders (Juckett and Hancox, 2002). The intoxication degree is estimated according to the appearance of these symptoms: 1) no intoxication("dry" bite); 2) mild intoxication (local edema and pain); 3) moderate intoxication (pain, edema spreading out of the bite zone, and systemic signs); 4) severe intoxication (shock, severe coagulopathy and massive edemas) (Adukauskiene et al., 2011). The treatment of snakebites consists of supportive therapy (primary wound care, tetanus prophylaxis, antibiotherapy and elevation of the bitten site), administration of antivenom and treatment of complications (coagulopathy and surgical debridement of necrotic zone) (Khimani et al., 2013). This report describes a pediatric case - boy having been bitten on the left side of his face by a venomous snake from Viperidae family.

\section{Case report}

A six-year-old boy was admitted to our emergency department two hour after having been bitten on the left side of his face by a venomous snake when he was looking around in their home's balcony. Initial clinical examination revealed a confused patient with severe pitting edema starting in the left half of his face and spreading towards neck (Figure 1). Patient's tongue and uvula were also edematic and inspiratory stridor was present. Pulse $\mathrm{O}_{2}$ saturations was $88 \%$. The patient was orotracheally intubated with a small-sized $(4.5 \mathrm{~F})$ endotracheal tube in the emergency department after atropine $0.2 \mathrm{mg}$, midazolam $2 \mathrm{mg}$, and vecuronium $4 \mathrm{mg}$ were administered intravenously and mechanical ventilation was initiated. Blood pressure was $70 / 50 \mathrm{~mm} \mathrm{Hg}$, heart rate was 145 beats per minute and sinus tachycardia rhythm was seen in the electrocardiography (ECG) examination. Respiratory rate was 36 breaths/min and auscultation of the lung fields was normal. Laboratory investigation results at the time of admission included a serum glucose level of $136 \mathrm{mg} / \mathrm{dl}$, in blood gas analyses, $\mathrm{pH}$ 7.18; $\mathrm{HCO}_{3}$ 16.4; $\mathrm{pCO}_{2} 44 \mathrm{~mm} \mathrm{Hg}$; $\mathrm{pO}_{2} 76 \mathrm{~mm} \mathrm{Hg}$; and white blood cell count 10 300/microliter; platelet count $189000 /$ microliter; and other laboratory findings present in Table 1. Other serum 


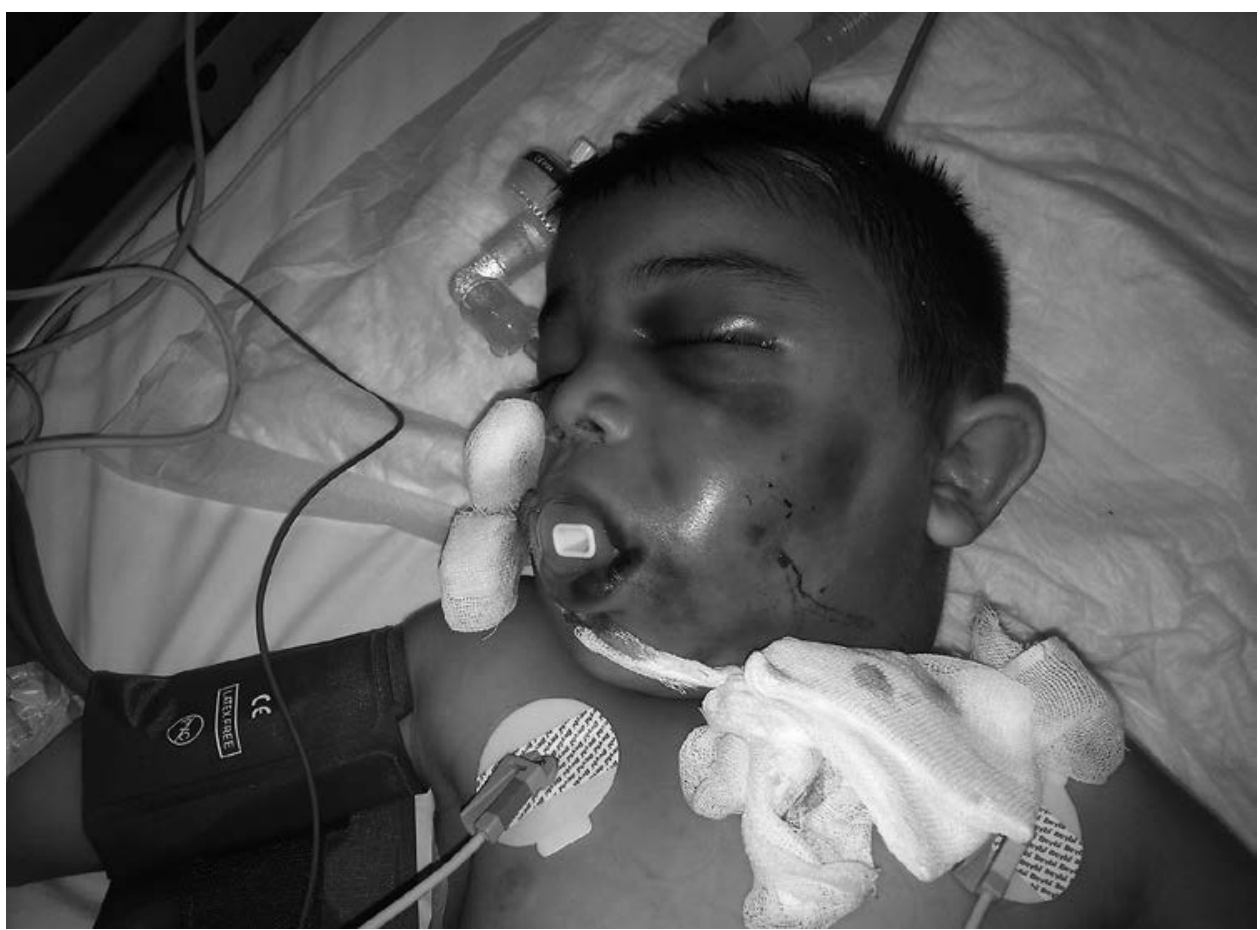

Figure 1 - Initial clinical examination revealed a confused patient with severe pitting edema starting in the left half of his face and spreading towards neck.

chemistry results were within normal limits. Evaluating local and systemic clinical findings together with laboratory test results, the patient was considered to be grade 4 , severe envenomation. Following treatment was given as follows; fluid replacement therapy with isotonic normal saline solution $(0.9 \%)$ was given at a dose of $20 \mathrm{cc} / \mathrm{kg}$ in $20 \mathrm{~min}$ and 4 flacon snake antivenom/250 cc isotonic saline in one hour (equine, European Institute of Immunology, Zagreb, Croatia), intravenous amoxicilline-clavulanic acid for antibiotherapy $(40 \mathrm{mg} / \mathrm{kg})$ and mannitol was given at $1 \mathrm{~g} / \mathrm{kg}$ for $40 \mathrm{~min}$ in the other arm. The patient was re-evaluated after forth hour of treatment. Because no improvement occurred in patient's edema, the mannitol $(20 \%, 4 \times 1 \mathrm{~g} / \mathrm{kg}$ ) and antivenom treatment (4 flacon) infused over one hour and the patient was transported to the intensive care unit. The patient was still orotracheally intubated after the second day of admission. Coagulation parameters and hemoglobin values were not within normal limits (Table 1), thus fresh frozen plasma (FFP) at a dose of $15 \mathrm{cc} / \mathrm{kg}$ in one hour and erythrocytes suspension $(15 \mathrm{cc} / \mathrm{kg}$ ) were administered. Additionally, $3 \times 2$ flacons (a total of 6 grams) of antivenom were administered. After the treatment, patient's laboratory findings were normalized (Table 1). The third day of the admission, edema was regressed, 


\section{Table 1 - Laboratory findings}

\begin{tabular}{lcccc}
\hline Day & $\mathrm{Hb}(\mathrm{g} / \mathrm{dl})$ & $\mathrm{Htc}(\%)$ & $\mathrm{PT}(\mathrm{s})$ & PTT $(\mathrm{s})$ \\
\hline 1. & 9.2 & 27.8 & 21.1 & 49.5 \\
2. & 7.7 & 21.5 & 25.5 & 78.2 \\
3. & 9.6 & 28.0 & 16.7 & 23.0 \\
7. & 10.5 & 31.5 & 14.5 & 22.0 \\
\hline
\end{tabular}

$\mathrm{Hb}$ - hemoglobin; Htc - hematocrit; PT - prothrombin time; PTT - partial thromboplastin time

antivenom administration was not given and the patient was extubated after remaining in T-tube for 8 hours. The mannitol dosage was gradually decreased and stopped and the patient was transported to the normal service for antibiotherapy and fluid replacement therapy. Seven days after admission, the patient was discharged in a good condition (Figure 2).

\section{Discussion}

After a venomous snakebite, the venom is activated by body temperature and tissue $\mathrm{pH}$. Crotaline venoms are heterogeneous enzymes that cause 3 types of toxicity. Most obvious is local tissue cytotoxicity manifested as edema and necrosis

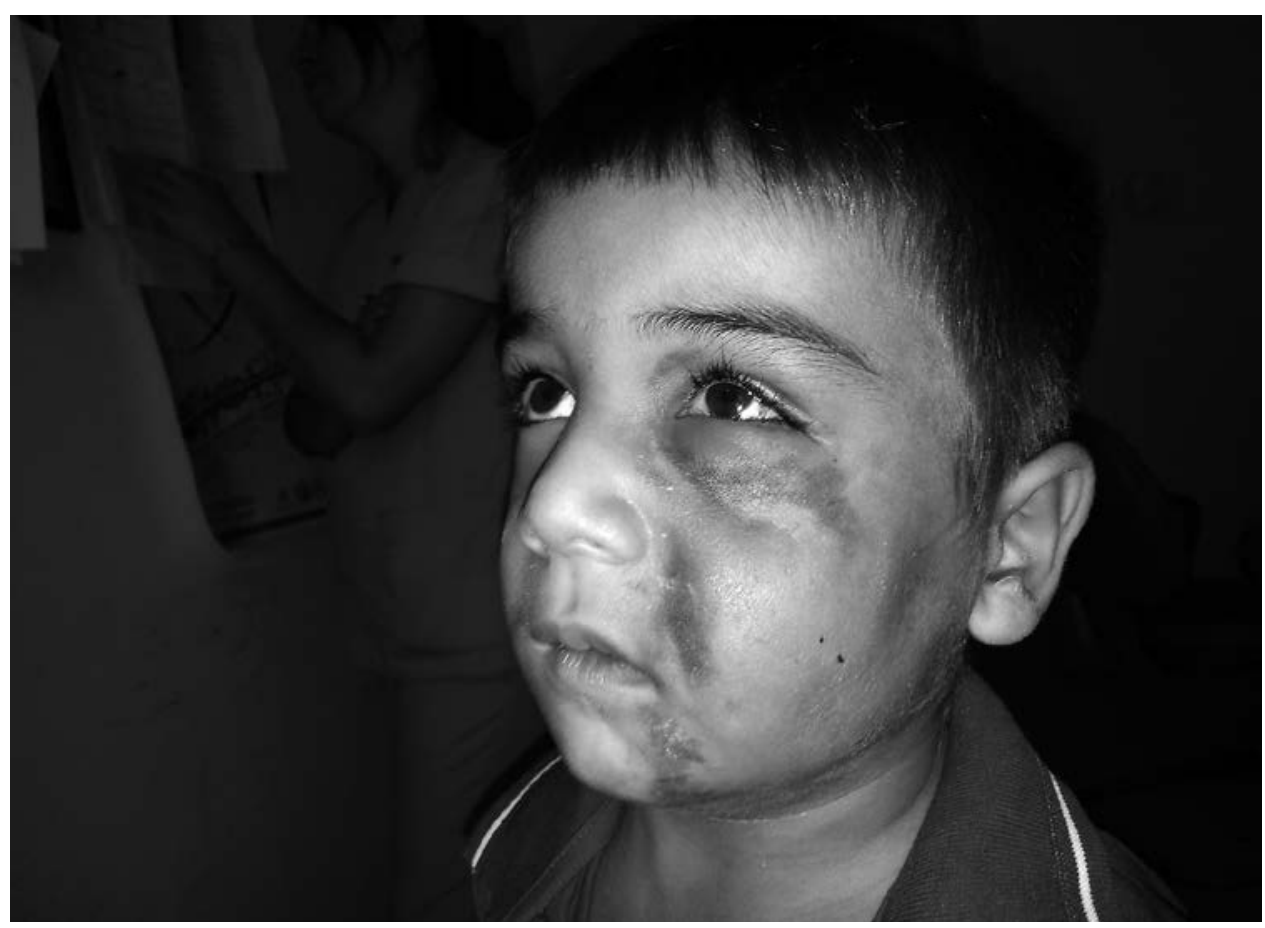

Figure 2 - Seven days after admission, the patient was discharged in a good condition. 
caused by direct cellular injury from venom components. Thrombocytopenia and coagulopathy, similar in appearance to disseminated intravascular coagulation, are typical hematologic findings. In certain rattlesnake species, neurotoxic symptoms may predominate. Ptosis, fasciculations, weakness, and eventually, paralysis may occur. The envenomation by Crotalidae species leads to local swelling in bitten site within 15-30 minutes but it may be longer (one to two days) according to severity of the case. In severe cases, edema can involve an entire limb within an hour. In addition to edema, life-threatening bleedings and coagulation disorders, renal failure and shock can be seen (Juckett and Hancox, 2002).

Traditional management of snake bites consists of aggressive supportive care (cleaning the wounds, fluid replacement, analgesia, tetanus toxoid, antibiotic therapy, extremity immobilizing - elevating) and antivenom therapy that is the mainstay of treatment (Gold et al., 2002). The factors in antivenom therapy are the size of edema, coagulopathy, shock or other systemic disorders. Thus, it is important to measure the border of edema in every 30 minutes. In moderate and severe envenomation, anti-snake venom should also be administered within 4 hours after snakebite but can still be effective within 24 hours. Antivenom neutralizes circulating venom, eliminating the toxic effects and thus effectively corrects clinical and laboratory signs; however, they are not necessarily effective as far as thrombocytopenia and rhabdomyolysis are concerned (Nuchpraryoon and Garner, 2000; Agency for Clinical Innovation, 2007; Kliegman et al., 2007; Norris, 2008; Warrell, 2010). Anti-snake venom is made by immunizing large animals, like horses, with venom or multiple venoms that often $(<10 \%)$ may cause acute hypersensitivity reactions because of their protein nature (Norris, 2008).

Fasciotomy is not routinely recommended but compartment pressure should be monitored closely. If it exceeds $30 \mathrm{~mm} \mathrm{Hg}$, fasciotomy should be performed. Facial Crotalidae envenomation is rarely reported (Pfeiffer and Price, 1976; Gerkin et al., 1987; Lewis and Portera, 1994; Tanen et al., 2001).

The vast majority of Crotalidae bites is located on the extremities that limbs below elbows or knees are the most commonly bitten body area (90\%), with less than $2 \%$ to the head or neck (Gerkin et al., 1987; Adukauskiene et al., 2011). A few cases of snake bites from face have been reported in the literature and most of them in adults (Pfeiffer and Price, 1976; Gerkin et al., 1987; Lewis and Portera, 1994; Tanen et al., 2001).

In a case of facial bite, nasotracheal intubation was required and antivenom was initiated but discontinued when allergic symptoms began despite treatment with methylprednisolone and triamcinolone. After 5 days of supportive care, the patient was discharged home without sequelae (Pfeiffer and Price, 1976). In a case of snake bites from tongues, patient required nasotracheal intubation, 35 total flacons of polyvalent antivenom, and was safely extubated 5 days after admission (Gerkin et al., 1987). In another case, patient was envenomated in the left cheek and nasotracheally intubated and received antivenom along with supportive care 
(Lewis and Portera, 1994). A 14-month-old female toddler was envenomated by Crotalus viridishelleri above the right upper lip. Oropharyngeal edema necessitated emergent orotracheal intubation. A total of 16 flacons of antivenom were administered over 24 hours. The patient was extubated 5 days later (Richardson et al., 2005). Nevertheless, a 22-year-old man of Vipera berus snake bite to the forehead was reported. In this case, antivenom was not given because of high allergy risk. There was a persistent unilateral facial frontalis muscle paresis (Weinelt et al., 2002).

In our case, the child was bitten on the left side of its face by a venomous snake when he was looking around in their home's balcony. Two hours after having been bitten, respiratory distress developed due to severe swelling in uvula, face and neck areas (Figure 1). Aggressive snake antivenom administration and supportive care are fundamental interventions necessary to prevent snake envenomationinduced morbidity and mortality. In contrast to our case, antivenom was not given in the case of Weinelt et al. (2002) and persistent unilateral facial frontalis muscle paresis developed subsequently (Richardson et al., 2005). In other cases, despite the antivenom therapy, patients were able to be extubated after at least 5 days and mannitol was not given in these cases (Lewis and Portera, 1994; Weinelt et al., 2002). In another study, mannitol was used as monotherapy and successful results were obtained (Anil et al., 2011). Therefore early orotracheal intubation was performed and mannitol infusion was started to decrease airway tract edema at the same time together with antivenom administration in our case. The patient was extubated on third day. We think that mannitol may reduce the duration of orotracheal intubation by decreasing the airway edema.

\section{Conclusion}

Here a rare case of a pediatric patient with a rattlesnake envenomation to the face that required emergent orotracheal intubation to prevent airway obstruction is presented. We think that early airway protection, intravenous crotaline Fab antivenom therapy, and simultaneous mannitol administration is a successful combination in this case.

\section{References}

Adukauskiene, D., Varanauskiene, E., Adukauskaite, A. (2011) Venomous snakebites. Medicina (Kaunas) 47, 461-467.

Agency for Clinical Innovation (2007) Snakebite and Spiderbite Clinical Management Guidelines. NSW Department of Health, North Sydney.

Anil, A. B., Anil, M., Kara, O. D., Bal, A., Özhan, B., Aksu, N. (2011) Mannitol therapy in three cases with severe edema due to snakebite: case report. Turk. Klinikleri J. Med. Sci. 31, 720-723.

Baran, I. (2005) Türkiye Amfibi ve Sürüngenleri Tubitak Popüler Bilim Kitapları. Bașvuru Kitaplığı, Ankara.

Gerkin, R., Sergent, K. C., Curry, S. C., Vance, M., Nielsen, D. R., Kazan, A. (1987) Life-threatening airway obstruction from rattlesnake bite to the tongue. Ann. Emerg. Med. 16, 813-816.

Gold, B. S., Dart, R. C., Barish, R. A. (2002) Bites of venomous snakes. N. Engl. J. Med. 347, 347-356. 
Juckett, G., Hancox, J. G. (2002) Venomous snakebites in the United States: management review and update. Am. Fam. Physician 65, 1367-1374.

Khimani, A., Mcnierney, A., Surani, S., Surani, S. (2013) Snake envenomation causing distant tracheal myonecrosis. Case Rep. Pulmonol. 2013, 364195.

Kliegman, R. M., Stanton, B. F., St. Geme, J.W. III., Schor, N. F., Behrman, R. E. (2007) Nelson Textbook of Pediatrics. Saunders, Philadelphia.

Lewis, J.V., Portera, C.A. Jr. (1994) Rattlesnake bite to the face: case report and review of the literature. Am. Surg. 60, 681-682.

Norris, R. L. (2008) Venomous snakebites in North America. In: Emergency Medicine. Adams, J. G., Saunders, Philadelphia.

Nuchpraryoon, I., Garner, P. (2000) Interventions for preventing reactions to snake antivenom. Cochrane Database Syst. Rev. 4, CD002153.

Pfeiffer, R. B. Jr., Price, V. G. (1976) Case report: Recovery from western diamondback rattler bite to mouth. Postgrad. Med. 59, 283-286.

Richardson, W. H. $3^{\text {rd }}$, Barry, J. D., Tong, T. C., Williams, S. R., Clark, R. F. (2005) Rattlesnake envenomation to the face of an infant. Pediatr. Emerg. Care 21, 173-176.

Tanen, D. A., Ruha, A. M., Graeme, K. A., Curry, S. C., Fischione, M. A. (2001) Rattlesnake envenomations: unusual case presentations. Arch. Intern. Med. 161, 474-479.

Warrell, D. A. (2010) Guidelines for the Management of Snake-bites. World Health Organization, New Delhi.

Weinelt, W., Sattler, R.W., Mebs, D. (2002) Persistent paresis of the facialis muscle after European adder (Vipera berus) bite on the forehead. Toxicon 40, 1627-1629. 